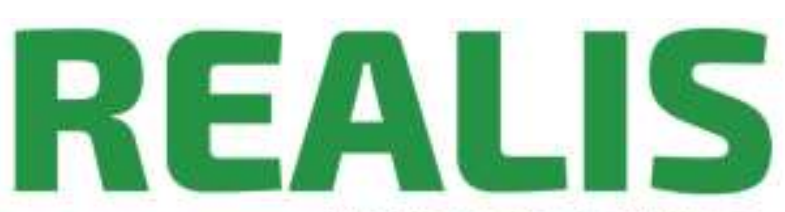

Revista de Estudos

AntiUtilitaristas e PosColoniais

\title{
O ESPAÇO-TEMPO ORIENTAL COMO ESPAÇO EXISTENCIAL | arquiteturas no Japão e na China ${ }^{1}$
}

\author{
Eastern space-time as existential space: architecture in Japan and China
}

COUTINHO, Walkyria Tsutsumi F.2

BRITTO LEITE, Maria de Jesus de ${ }^{3}$

\begin{abstract}
Resumo: 0 presente artigo tem como desafio realizar um paralelo entre Oriente e Ocidente, focando nos significados de espaço como lugar da vivência humana. Discute no campo da Arquitetura, sob o entendimento que o espaço é sua matéria primeira que carrega a condição de possibilidade de interferir significativamente nas subjetividades individuais e coletivas, intrinsecamente nas culturas de cada povo. Atravessa conhecimentos multidisciplinares da Linguística, da Filosofia, da Arte e da teoria da Arquitetura para refletir sobre que aspectos da vida cotidiana, das culturas locais, participam das compreensões arquitetônicas no Japão e na China. Ao reconhecer a subjetividade e as vivências de cada cultura como indissociáveis das compreensões de espaço e de tempo, assume que a fenomenologia da arquitetura é aquela que mais possibilita esse exercício e por isso transita por autores que têm afinidades com a fenomenologia, enquanto modo de pensar o mundo.
\end{abstract}

Palavras-chave: Japão; China; Fenomenologia da arquitetura; espaço e tempo existenciais.

Abstract: The challenge of this article is to make a parallel between East and West, focusing on the meanings of space as a place of human experience. It discusses the field of Architecture, under the understanding that space is its primary matter that carries the condition of the possibility of significantly interfering in individual and collective subjectivities, in the cultures of each person. It's through multidisciplinary knowledge of Linguistics, Philosophy, Art and Theory of Architecture to reflect on what aspects of daily life, of local cultures participate in architectural understandings in Japan and China.

\footnotetext{
${ }^{1}$ Enviado em: 23 Out 2021. | Aceito em: 10 Nov 2021.

${ }^{2}$ Arquiteta e Urbanista. Mestre em Desenvolvimento Urbano-Universidade Federal de Pernambuco (MDUUFPE). Professora do Curso de Arquitetura e Urbanismo da Universidade Católica de Pernambuco. http://orcid.org/0000-0002-2023-8441.Email: walkyria.tsutsumi@ufpe.br

${ }^{3}$ Arquiteta e Urbanista. Mestre e Doutora em Arquitetura e Urbanismo pela Faculdade de Arquitetura e Urbanismo da Universidade de São Paulo (FAU-USP). Professora do Programa de Pós-Graduação em Desenvolvimento Urbano - MDU-UFPE. Coordenadora do Laboratório de Investigação do Espaço na Arquitetura - LIA | UFPE. http://orcid.org/0000-0002-3284-1280. Email: juju.institutofuturo@gmail.com

REALIS | Digital Object Identifier (DOI): 10.51359/2179-7501.2021.252150 
Recognizing the subjectivity and experiences of each culture as inseparable from the comprehension of space and time, he assumes that the phenomenology of architecture is the one that most makes this exercise possible and that is why it moves through authors who have affinities with phenomenology, as a way of thinking the world.

Keywords: Japan; China, phenomenology of architecture; existential space and time.

\section{Introdução}

O espaço como o lugar da vivência humana é uma discussão que acontece no campo da arquitetura e do urbanismo em pelo menos duas perspectivas: a) que o espaço, enquanto expressão estética é a matéria primeira da arquitetura; b) que o espaço carrega a condição de possibilidade de interferir significativamente nas subjetividades dos indivíduos, das coletividades, das culturas. No nosso caso, buscamos perceber nas discussões arquitetônicas do Japão e da China, o que se constitui na dificuldade epistemológica deste artigo: observar culturas distintas da nossa. As reflexões atravessam conhecimentos multidisciplinares e buscamos apoio na Linguística, sobre significados caros às reflexões em arquitetura, urbanismo e paisagismo - o habitar, a relação espaçotempo, o sentido de lugar - por serem termos que vinculam o espaço à sua relação mais vivencial. Partilhamos a possibilidade de, ao ampliar os horizontes, podermos refletir de modo mais acurado sobre o espaço, nas culturas japonesa e chinesa, e cotejá-lo com o entendimento contido na fenomenologia da arquitetura, que se constitui como um modo de entender que vai além da tectônica e da funcionalidade; inseparável da condição simbólica e cultural.

Nos apoiamos em Augustin Berque, estudioso da China e do Japão para discutir como as espacialidades das arquiteturas expressam o sentimento de mundo; como a relação entre tradição e contemporaneidade acontece; como estas questões permeiam teorias da arquitetura, do urbanismo e do paisagismo. Buscamos perceber como essas duas culturas traduzem esses significados de origem, e como permitem aportes significativos à Arquitetura. Iniciamos por reconhecer na composição dos ideogramas, uma compreensão não funcionalista, mas perceptiva dos significados de espaço. Em seguida, trazendo essas simbologias para a Arquitetura, tecemos considerações sobre diferenças e semelhanças de entendimento, de modo a contribuir para o alargamento desse conhecimento. Nossos principais pensadores arquitetos são Arata Izozaki e 
Christian Norberg-Schulz e tentamos exemplificar nossas percepções sobre este diálogo, com obras contemporâneas, à luz da relação entre cultura e fenômeno do lugar.

\section{Desenvolvimento}

\section{Entendimentos de espaço e de tempo, através da linguística}

Ao analisarmos os termos através da linguística, percebemos a necessidade de compreender suas similitudes e potenciais aplicações na arquitetura contemporânea, e para isso, nos propomos relacionar teorias e conceitos, entendendo como Saussure que "uma palavra pode ser 'trocada' por uma ideia; mas também é possível compará-la com outras palavras" (Saussure, 1975, p. 22). Por sua vez, em "Construir, habitar, pensar", Martin Heidegger analisa a relação entre o construir e o habitar (1951), define o habitar como "um permanecer com as coisas" e elege a linguagem como ancoragem cultural. Nesse sentido Norberg-Schulz, ao integrar a fenomenologia a arquitetura na teoria do espaço existencial, diz que "o homem habita a linguagem": [...] 0 homem habita na linguagem, isto é: quando ouve e responde a linguagem, o mundo que ele é se abre, e uma existência autêntica se torna possível (Norberg-Schulz in NESBITT, 2013, p. 466).

Essas referências focam tanto na importância da língua para se reconhecer uma cultura, como na intrincada relação entre espaço e vivência, expressa no termo "habitar", de modo concreto, não representacional. Isso nos permitiu o seguinte argumento: buscar os significados de espaço e de tempo que estão embutidos nos ideogramas japoneses e chineses pode nos aproximar do modo de pensar e de agir, dos orientais. A escrita, por meio de ideogramas, possui significados profundos se comparados ao Romaji, como os orientais se referem ao alfabeto ocidental, sendo tão crucial para a compreensão o significado da palavra quanto o entendimento dos símbolos que a constitui. 0 Kanji nasceu na China e significa "caracteres da dinastia Han", na escrita chinesa oficial. Na China, todas as palavras são escritas em kanji, enquanto no Japão, somente os elementos mais significativos da sentença, que se somam aos alfabetos hiragana e katakana (Coutinho, 2015).

Entre os arquitetos japoneses, o $M A$ é o ideograma adotado como símbolo do entendimento de espaço. Ele corresponde a uma composição de duas portinholas, através 
das quais, no seu "entre-espaço", avista-se um feixe de luz para o sol. Este símbolo das duas portinholas, que literalmente significa "porta", é um dos símbolos que se manteve desde o início da escrita kanji (Chou, 1986)

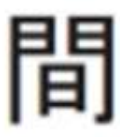

$\mathrm{Ma}$

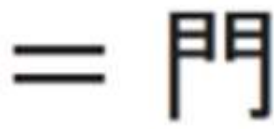

Portinhola

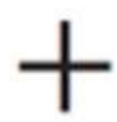

Sol

O ideograma $M A$ foi retomado na contemporaneidade da arquitetura do Japão, como um conceito arquitetônico que simboliza a expressão e apreciação espaciais, que considera a importância não apenas funcional, mas existencial, pois denota a relação luz e sombra, a consciência dos percursos percebidos, os lugares, traduzindo um modo de viver característico.

Ken Tadashi Oshima (2009), historiador de arquitetura do Sainsbury Institute Fellow, Londres, discorre sobre o MA:

A representação do $M a$ caligraficamente entre dois portões configura uma repetição que evoca espacialidade como uma experiência aberta e perceptual. Jardins japoneses, como o Ryoanji, são caracterizados por um espaço integrado ao meio ambiente, que são animados pela chuva, vento e outras forças naturais. 0 tempo aqui não é linear e sim cíclico como um componente inerente do conceito Ma. (ISOZAKI \& OSHIMA, 2009: p. 1018. T.N.).

A palavra $M A$ é ainda definida como os significados ocidentais de tempo e espaço, exprimindo tanto "tempo" quanto "espaço" através da noção de intervalo. O MA é a base para entendermos todas as esferas do ambiente, da vida e da arte - arquitetura, belas artes, música, teatro e paisagem. Assim, segundo Isozaki,

Esta forma única de percepção espacial no Japão deu origem a um sentido de vida diária e expressão artística que difere fundamentalmente do Oeste. Se alguém toma isso como um extremo, o conceito de espaçotempo no Oeste deu origem a imagens fixas de um contínuo homogêneo e infinito, como apresentado por Descartes, que se tornou a base para concepções modernas. No entanto, o espaço e o tempo no Japão eram partes onipresentes e mutuamente responsivas. Numa condição caótica, misturada, o espaço não pode ser percebido independentemente do elemento de tempo. Da mesma forma, o tempo não foi captado como um fluxo homogêneo regulamentado, mas sim se acreditava existir apenas em relação aos movimentos ou espaços. (ISOZAKI, 2009: p.156-161 T.N.).

Entre os chineses, embora não exista um símbolo único, como no caso japonês, para se referirem ao espaço arquitetônico, alguns termos podem ser reconhecidos - entre 
eles, Jia - que tem sentido de casa, e pode ser encontrado na composição de palavras como guojia (país de origem); laojia (seu lugar original), ou com várias outras expressões sempre relacionadas ao sentido cultural de pertencimento a um lugar, a uma vivência doméstica. Também o termo Xiang, que tem o sentido de "lar" no contexto dos moradores do campo, mas que também pode ser traduzido como "município".
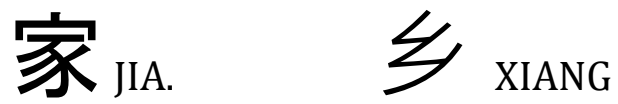

Muitos ideogramas demonstram uma compreensão que nos permite entender significados de espaço, de lugar e vamos tentar interligá-los. O ideograma Jia parece se aproximar de uma reflexão sobre o espaço da arquitetura, de um ponto de vista fenomenológico: este caractere é coroado pelo símbolo $\boldsymbol{~}$, que significa telhado, e que também pode significar "em casa"4; expressa no pensamento chinês o que é concreto, no sentido referido por Trigoso (2006) de "concrescência do espaço e do tempo" (Trigoso, 2006: nota 17).

A palavra Kōngjiān, Espaço, em chinês tradicional (空間), contém o símbolo do telhado na composição do Kōng, ar, céu, + Jian, pausa, entre atos, (MA, para os japoneses) aparece com o símbolo , que parece também significar o que é concreto. De acordo com Trigoso (2006), a indissociabilidade entre tempo e espaço também é um aspecto fundamental na tradição chinesa, na medida que a palavra yuzhou, que pode ser entendida como "tempo", é composta de dois caracteres - 時 + 間 - que significam, respectivamente, "mundo enquanto extensão" e também do Jian (MA), que assume o sentido de "mundo enquanto duração". Para a pesquisadora, os chineses conceberam não um espaço ou um tempo em si, mas aquilo que, no Ocidente, poderia ser denominado de "locais" e "ocasiões".

Diferentemente do tempo linear ocidental, o tempo chinês não aparece como uma duração monótona, por ser constituída pela sucessão de momentos qualitativamente iguais, mas como um conjunto de diferentes eras, estações ou épocas. Cada um destes períodos possui rubricas

\footnotetext{
${ }^{4}$ A língua chinesa é reconhecida como orgânica, viva, e daí que os caracteres assumem muitos significados na composição de palavras e de frases. A palavra 安 [ān] 'paz' é a combinação de $\dot{\sim}$ [mián] 'telhado' e 女 [nǔ] 'mulher', significando que "tudo é pacífico com a mulher em casa". https://www.epochtimes.com.br/aprenda-chines-caracteres-chineses-introducao/ acessado em 28/03/2021.
} 
simbólicas e atributos próprios que lhes dão uma consistência particular e os individualizam uns dos outros. (TRIGOSO, 2006).

Mas Trigoso nos relata que mesmo com o entendimento da indissociabilidade espaço-tempo, os chineses precisaram criar uma tradução para o que significa "tempo", entre os ocidentais, no final do século XIX, como uma forma de aproximação entre culturas: o neologismo shijian ( 是见 ), que significa literalmente “entre-momentos" e representa a ideia - estranha para os orientais - de lapso de tempo, com um ponto de partida e outro de chegada, diferentemente de uma manifestação infinita e contínua, como é próprio do pensamento oriental e bem analisado por Trigoso:

[...] o pensamento chinês não apreendeu a natureza como movimento, à semelhança de Aristóteles, mas como interação permanente entre energias opostas e complementares (o yin e yang). Não separando o temporal do atemporal, a China não concebeu o eterno, mas o constante.

Tal como o eterno, a noção de chang também denota a permanência, mas fá-lo de outra forma já que não remete para o ser, isto é, para o fora do tempo, mas para a viabilidade e não interrupção dos processos. 0 constante, que se manifesta através do que muda, é da ordem da capacidade e corresponde à virtude natural das próprias coisas. No mundo chinês não encontramos qualquer separação entre a aparência e o que seria, por oposição a esta, a sua essência, ou Ser, na qual se funda a metafísica. (Trigoso, 2006).

Shijian também pode ser traduzido como "homem no espaço", reforçando a condição da existência humana como um fenômeno vivido, e nos permite este exercício de aproximação linguística entre as culturas do Oriente e do Ocidente, via a Fenomenologia. Para a Fenomenologia, homem e espaço são indissociáveis, pois não há como pensar na existência humana sem sua existência espacial. Ao mesmo tempo, os estudiosos dos ideogramas orientais registram que há uma relação intrincada entre o vocabulário e a filosofia. 0 fato de a construção das frases independerem de focar em sujeitos da ação (ao contrário do Ocidente), expressa seu modo de refletir sobre a existência:

A possibilidade de dispensar o sujeito em chinês torna mais fácil imaginar o cosmos num perpétuo processo circular de transição, sem necessidade de postular um agente externo para atuar ou controlar o processo. É um conceito-chave da cosmologia chinesa (Chou, 1986: p. 246).

Enfim, observar os ideogramas nos pareceu um primeiro passo para tentar entender a cultura oriental, no caso, dos chineses e japoneses. Por exemplo, Trigoso, ao se referir aos estudos de Wu (1995), diz: "Ele mostra como o espaço é definido pelo tempo 
vivido (leva tempo ir de 'aqui' para 'ali') e o tempo é definido pelo espaço experimentado (sem a progressão do 'isto' para o 'aquilo' não haveria espaço) (in Trigoso, 2006: Nota 14).

\section{Espaço e tempo fenomenológicos como aproximação cultural}

Quando percebemos o modo de ser oriental, onde o presente é fundamental, o tempo é cíclico, sem focar em chegadas e partidas, e onde as subjetividades são percebidas como algo concreto da vida, nos parece que a Fenomenologia pode aproximar Oriente e Ocidente. Considerando que é em Heidegger que Christian Norberg-Schulz busca os argumentos filosóficos para conceber sua Teoria do Espaço Existencial, também podemos entender a condição concreta que reside na compreensão subjetiva de espaço, de tempo e vivência, que se aproxima com o modo de entender oriental. Norberg-Schulz traduz a fenomenologia para a arquitetura, entendendo o espaço como existencial, cujo objetivo primordial é tornar o mundo visível, concreto. Em seu livro Existence, Space and Architecture (onde ele constitui sua teoria) e, em Arquitectura Ocidental (1999), onde ele pratica sua teoria), Norberg-Schulz reafirma a condição existencial do espaço. Em "Arquitectura Ocidental", seu prólogo se apresenta como um manifesto, porque expressa, numa visão ocidental, o que está concretizado:

A Arquitetura é um fenômeno concreto. Consiste em paisagens e assentamentos, edifícios e articulações caracterizadoras e por isso é uma realidade vivente. Desde os tempos remotos, a arquitetura tem ajudado o homem a dar significado à existência.

Mediante a arquitetura, conquistamos um equilíbrio no espaço e no tempo... Em consequência, a Arquitetura transcende as necessidades práticas e a economia. Se ocupa dos significados da existência. Os significados existenciais derivam dos fenômenos naturais, humanos e espirituais.

[...] Em arquitetura, forma espacial significa lugar, percurso e área. Ou seja, a estrutura concreta do ambiente humano. [...]A Arquitetura deve ser entendida em termos de formas significativas (Norberg-Schulz, 1999: $p$ 7)

Esta teoria propõe a inseparabilidade entre ser humano e espaço, se apoiando no conceito filosófico ser-no-mundo, de Heidegger, que significa pertencer a algum lugar, e que, expresso como uma palavra composta reafirma a condição de inseparável. Segundo Padua, Heidegger refere-se a fenômenos importantes, para o diálogo entre Ocidente e Oriente:

"Os fenômenos do demorar-se (Verweilen) e do não ir embora (Nichtweglaufen). É significativa a escolha destes dois fenômenos especificamente: o demorar-se, o permanecer junto, o caráter de ser-aí- 
junto-a (Da-bei-seins) é a condição para o habitar, para o pertencimento a um determinado lugar (Heidegger in Padua, 2005: p. 24).

Trata-se de um modo de refletir sobre a experiência no mundo e sobre a inseparabilidade entre ser humano e espaço. 0 filósofo orientalista e fenomenólogo, Augustin Berque (2010), adota três conceitos importantes para a nossa discussão:

1 - 0 conceito mediania, do filósofo japonês Watsuji Tetsuro, que significa "o momento estrutural da existência humana" e se refere a junção de duas metades que formam o ser humano: "seu corpo animal, que é individual, e seu corpo medial, quer dizer, o meio que ele partilha com outros seres humanos e que lhes é, portanto, comum". Berque reflete sobre a diferença entre identidade e identificação, indo buscar na filosofia clássica os termos topos, gênesis e chora:

É essencial que diferenciemos chôra, de topos, embora as duas palavras gregas possam se traduzir, em francês, como "lugar". [...] 0 topos é como um vaso imóvel que contém a coisa, e que não muda de lugar, mesmo se a coisa for levada para outro lugar. Ao contrário, a chôra e a Genesis não podem se separar. Dito de outro modo, no Timeo, o lugar participa do ser, enquanto na Physique eles são diferentes (Berque, 2010).

2 - Retoma do passado o entendimento de locus communis, que significava um argumento que podia ser aplicado a diferentes assuntos, ou também, "lugares de argumentos", do ponto de vista da Estética. Segundo Berque, esses "lugares de argumentos" estão traduzidos no termo japonês mitate, que significa "ver como", e se trata da "identificação" com o lugar, e não de uma "identidade". Diferenciar "identidade" de "identificação" importa para a discussão sobre a inseparabilidade entre o ser humano e seu habitat. Ao demonstrar que o ser humano participa do lugar e o lugar participa do ser humano, Berque diz: "É porque cada um de nós possui a identidade de um corpo individual, sempre identificados a um meio comum, que somos plenamente humanos, e que podemos estabelecer relações com as coisas" (Berque, 2010).

3 - Adota o conceito "ciência naturante", do pensador Imanishi Kinji, que se opõe ao dualismo ocidental, que, segundo ele, transforma a natureza em objeto. Reforça nosso argumento de buscar apoio na linguística, ao se referir a realidade e a contingência da ligação entre "língua" e "visão de mundo, que se revela pelo que ele denomina de "motivação", ou, "uma relação ternária onde A se torna B em função de C", diferente da relação binária ocidental. Esta noção vem do Budismo, da ideia de que nada é substância, tudo é relação. Berque assinala que esse é um modo que está expresso na base da língua 
japonesa. Ou seja, Berque, apoiado em Kinji, entende a subjetividade como contribuidora da história evolutiva da Humanidade. Uma reafirmação da Mediania, de Watsuji e do entendimento de locus communis como lugares de argumento.

Se consideramos como os ideogramas são compostos em seus significados, nossa percepção é que a partir do conceito fenomenológico japonês, "mediania" (e de sua relação com os dois outros conceitos - locus communis e ciência naturante) e do entendimento de "ser-no-mundo", da fenomenologia ocidental, podemos estabelecer uma conjunção entre Oriente e Ocidente, apoiando-nos no "espaço existencial" de NorbergSchulz, para trazer a discussão para a Arquitetura. Mesmo que o "Ser" não faça parte das reflexões filosóficas orientais; que o Tempo lhes seja um termo pouco afeito, se retomarmos o que diz Trigoso (2006) sobre a concrescência do espaço-tempo; sobre a relação entre o ser humano e o mundo como uma interação, expressa também na complementaridade do yin e do yang, podemos verificar como a arquitetura no Japão e na China podem dialogar com a fenomenologia da arquitetura do Ocidente. Exemplo disso é que o $M a$ japonês e o Shijian chines, se referem a dimensão do lugar, como existência concreta, simbolicamente representada nos seus ideogramas.

\section{Tradição e modernidade no pensamento arquitetônico oriental: o caso do Japão}

A aproximação dos significados de tempo e espaço entre Oriente e Ocidente, considerando o esforço chinês em construir a palavra "tempo", ainda no século XIX, tem em Arata Isozaki seu maior responsável. 0 contexto cultural de discussão teórica no Ocidente, com as críticas ao movimento moderno, focava na busca por um novo entendimento de "espaço". Em 1941, Siegfried Giedion publicou "Space, Time and Architecture", onde afirmava que "pela primeira vez, desde o Renascimento, uma nova concepção de espaço conduz(ia) conscientemente ao alargamento das nossas capacidades perceptivas" (Giedion, 2004: p. 455). Nas Artes, o Cubismo propunha a integração de espaço e tempo, sendo formulada por Hermann Minkowski, em 1908: “de agora em diante, espaço ou tempo, como entidades isoladas e autônomas estão condenados a desaparecer como sombras: somente uma forma qualquer de união entre ambas será capaz de preservar a sua existência" (In Giedion, 2004: p. 749). Conhecer o movimento Cubista fez com que Giedion, encontrasse naquelas obras de arte um exemplo de integração espacial e temporal, expressos pelo movimento e fragmentação dos objetos 
representados, e vislumbrasse as fundações de uma nova consciência artística, onde o "tempo", surge para romper com os antigos paradigmas renascentistas.

[...] Ao dissecar os objetos, percebe-os simultaneamente, por todos os lados - por cima e por baixo, por dentro e por fora, circundando-os e penetrando-os. [...] As três dimensões do Renascimento, que haviam se mantido como fatos constituintes por tantos séculos, é acrescentada a uma quarta - o tempo (GIEDION, 2004: p. 746-749).

Foi nesse cenário que Arata Isozaki declarou seu compromisso com a epistemologia. Inspirando-se na quarta dimensão espacial de Minkowski, manifestou a impossibilidade de distinção entre tempo e espaço:

A arquitetura pode ser teorizada como a convergência dos conceitos ocidentais de tempo e espaço. 0 ambiente que nos rodeia está em um estado de transformação impulsionado por aquilo que poderia ser chamado de um lugar de grau zero, em que não apenas entidades físicas, mas também as estruturas sociais estão sendo continuamente destruídas e desmanteladas. Tentei resgatar tais entidades como partes de um processo, a cidade, arquitetura e estilos de vida. (in ISOZAKI, Arata \& OSHIMA, Ken, 2009: p. 07 T.N.).

Para os japoneses, MA é um modus operandi cotidiano, apresentando-se em todas as manifestações culturais, de maneira que a construção do conhecimento se faz mais pela percepção do que pela razão. Orientalistas reforçam a importância desta escolha pelo $M A$ como orientadora da arquitetura japonesa:

a) Augustin Berque (2001) diz que $M A$ se torna incontestável para a noção moderna de espaço, por seu significado universal: "No espaço concreto da existência humana, a distância entre as coisas assegura a singularidade da experiência, tanto na escala de uma vida, quanto da história: o que dá um valor contingente, irredutível, a esse modelo abstrato é o sistema métrico" (BERQUE, 2001: p. 69-70);

b) Gunter Nitschke, em "From Shinto to Ando. Studies in architecture antropology in Japan", ao abordar o MA junto a elementos fenomenológicos ocidentais, diz que o lugar é um produto do espaço vivo e da incidência do tempo, um reflexo do estado de mente e alma do ser. (Nitschke, 1993: p. 51).

Em 1978, diante de poucos escritos acerca desse tema, Arata Isozaki organiza a exposição "MA: Espace-Temps du Japon", realizada em Paris. A exposição teve como iniciativa a sugestão do secretário da Embaixada da França no Japão para realização de um evento sobre o "espaço japonês". Segundo Isozaki, 
No Japão, os conceitos de espaço e tempo têm sido simultaneamente apreendidos pela única palavra " $M a$ ". Mas é, literalmente, definido como o intervalo natural entre duas ou mais coisas existentes em uma continuidade "ou" o fosso entre duas coisas, uma abertura; o espaço abrangido por colunas ou biombos ou a pausa singular ou intervalo em que os fenômenos surgem ao longo do tempo. (ARATA ISOZAKI, 2009: p.156)

A estratégia adotada por Isozaki correspondia a um modo típico japonês de aguçar múltiplos sentidos: visual, auditivo e tátil. Assim, a exposição compreendia uma variedade de elementos: objetos artesanais, fotografias, instalações, concertos, representações teatrais, dança, objetos do cotidiano, projeções de filmes e vídeos. Segundo Michiko, "o tema foi organizado para que o público, ao passar de um item a outro, experimentasse corporalmente um espaço-tempo de modo a provocar uma reação de sentidos em cadeia" (MICHIKO, 2007: p. 26). O objetivo da Exposição era apresentar o $M A$ como uma característica da cultura japonesa, de modo a ser compreensível para o Ocidente. Isozaki pretendia esclarecer que o conceito do $M A$, na compreensão japonesa, é uma função vital do cotidiano, e expresso nos gêneros artísticos. Todos os temas elegidos para representar o $M A$ permeavam várias esferas artísticas e foram selecionados de acordo com seu potencial de representar o conceito. Ao mesmo tempo, Isozaki tinha o $M A$ como um termo fluido, encontrado em vários aspectos objetivos e subjetivos da vida no Japão. Daí resultou a classificação em nove princípios sagrados, profanos e cotidianos, vivenciados na exposição como conceitos espaciais e temporais concretos que se referem a noção de lugar e de transmissão de significados; a conexão entre universos; a escuridão e a penumbra, ao desnorteamento, a desesperança; ao exato momento do movimento; ao lugar onde a vida é vivida; a consciência da passagem do tempo; a importância do lúdico; ao deslocamento no espaço. Com a exposição de 1978 e os posteriores escritos acerca do tema, Isozaki apresentava ao Ocidente o conceito $M A$ de forma holística, e presente em praticamente todos os segmentos da cultura.

Fazendo uma relação direta do $M A$ com a Fenomenologia, da mesma forma como Isozaki descreve o $M A$ em suas várias expressões, podemos lembrar com Norberg-Schulz, que em sua Teoria do Espaço Existencial, no "lugar", existem diferentes "lugares” em uma mesma obra de arquitetura. Desse modo,

Todos os lugares possuem um caráter: um habitat tem que ser protetor, um escritório tem que ser prático, um salão de baile, "festivo"; e uma igreja, "solene". Por isso, lugares são designados por substantivos, e isso 
implica dizer que os consideramos coisas reais que existem, que é o sentido original da palavra substantivo. [...] Caráter é, ao mesmo tempo, um conceito mais geral e mais concreto do que espaço. Ele denota uma compreensiva atmosfera geral, a forma concreta e a substância dos elementos de definição espacial. Qualquer tipo de presença humana está ligada a um caráter particular que resulta, também, das exigências específicas das diferentes ações inerentes ao ato de apropriação do Lugar. (Norberg-Schulz, 1991: p. 6-11 T.N.)

\section{Tradição e modernidade no pensamento arquitetônico na China}

Entre os arquitetos chineses também persiste a busca por uma arquitetura reconhecidamente chinesa, que expresse o diálogo entre modernidade e tradição, como conseguiram os arquitetos japoneses, a partir da adoção do $M A$. Vimos com os estudiosos da Linguística que todas as referências ao espaço trazem um enraizamento cultural muito forte e que a relação com o mundo existencial é imediata, na cultura chinesa. Os sentidos de casa, de origem, de lar, de vivência que residem nos ideogramas que se referem a "espaço", "lugar" e tempo; assim como os sentidos de terra, céu, de constância da vida, naqueles ideogramas que se referem a existência como algo concreto, confirmam o modo fenomenológico como o espaço é compreendido, seja edificado, urbano ou paisagístico. Também está expresso no cuidado com que as novas arquiteturas são concebidas de modo interdependentes ao sítio, ao modo de vida, à paisagem. Os estudos linguísticos permitem reconhecer nas novas posturas arquitetônicas e urbanísticas, os conceitos adotados por Berque $(2010,2015)$ de Mediania, de locus communis e de ciência naturante, que remetem a indissociabilidade homem-espaço, presentes na Fenomenologia de Heidegger - o ser-no-mundo - e na Fenomenologia da Arquitetura de Norberg-Schulz, quando ele define que "espaço = paisagem + assentamento". Construção teórica que afirma o lugar como aquele que acolhe as argumentações da vida cotidiana, os sentimentos dos viventes, para além de dormir, se alimentar, trabalhar; como aquele onde acontece a identificação do ser humano com o seu habitat.

Embora predomine na maioria das grandes cidades chinesas um aspecto urbano massificado, vem surgindo uma arquitetura significativa que consegue um diálogo entre tradição e contemporaneidade, de modo a expressar aqueles sentidos contidos nos ideogramas e no modo de ser chinês, seja na relação cidade preexistente - cidade contemporânea, ou nas formas e espacialidades novas. Naturalmente, a realidade urbana da China exige um compromisso forte com o urbanismo e com o paisagismo, dado que 
populações inteiras foram transferidas do campo para a cidade em curto espaço de tempo; e muitas cidades convivem com um urbanismo sino-soviético dos anos 1950; com uma arquitetura contemporânea aos moldes ocidentais; com a perda de centros urbanos antigos, motivada pela urgência em resolver o déficit habitacional e garantir habitabilidade nas cidades. Isso vem provocando muitas reflexões urbanísticas entre os arquitetos chineses.

A Bienal de Arquitetura de Shenzen, em 2017, por exemplo, foi organizada como espaço de reflexão e crítica das ações de planejamento adotadas até então, e provocou pesquisas sobre urbanismo, patrimônio e renovação urbana. As principais críticas focaram no excesso de verticalização e no modo como foram substituídas as "Urban Villages", bairros dos migrantes de outras regiões da China e que, a despeito dos problemas de infraestrutura, expressavam um modo de vida peculiar. A Bienal de Shenzhen, segundo Meng Yan (2017), tornou-se um marco no pensamento sobre requalificação urbana e desenvolvimento urbano sustentado. Outro exemplo são os estudos sobre os houtongs, conjunto de casas autoconstruídas em torno de pátios, que existem nos arredores da Cidade Proibida de Pequim. Um tipo compacto de bairro que, segundo Tella (2013), se compõe de vias de pouca largura, onde "o reduzido aproveitamento do solo, o sistema de transporte diferente, a relação natural com a paisagem, a rede de negócios, estabelecimentos e restaurantes constituem um sistema que alimenta as necessidades diárias dos residentes e forma elementos complexos de coesão social, relações e criatividade".

Mas não só o urbanismo tem suscitado a preocupação dos arquitetos. Por exemplo, o Journal of Architectural and Planning Research publicou um importante artigo de HsingChen Cheng and Chih-Ming Shih, intitulado Reinterpreting Traditional Chinese Architecture in the Office Building and Skycraper: The Archietecture of C. Y. Lee, que analisa as interpretações que o arquiteto C. Y. Lee faz da arquitetura tradicional, a partir do uso do telhado em balanço e do redesenho do dougong, um elemento estrutural que se apoia na intersecção de dois suportes de madeira e distribui o peso do balanço da coberta, comum nas arquiteturas chinesa, japonesa e coreana. Um dos arquitetos mais respeitados da China, Lee pratica um formalismo muito próximo do pós-moderno historicista ocidental, mas, uma ênfase nos sistemas construtivos ressalta o sentido de concreto do espaço e o redesenho das estruturas construtivas é um modo de dialogar com a tradição 
e a modernidade, garantindo um modo de viver. O Yingzao Fashi, são Normas de construção do Estado, o manual técnico chinês mais antigo, datado de 1103 (Miao, 2020) e que permanece em uso. Nele, as peças das estruturas são modulares, práticas e permitem rápida execução (Miao, 2020).

É possível reconhecer essa inter-relação em várias obras e atitudes dos arquitetos, como a recente biblioteca Satori Harbor, na cidade de Guangzhou. Segundo Miao (2021), "O nome "Satori" foi inspirado por um conceito cunhado pelo antigo filósofo Mestre Zhuang, que descreve o estado de espírito transcendental da prática do Taoísmo, quando a luz da manhã brilha sobre a superfície da Terra. 0 edifício acolhe espaços de leitura, meditação, e uma casa de chá. Todo o edifício é concebido como uma paisagem oriental. Também está expresso na escolha, por grupos de arquitetos, em se dedicar ao projeto em cidades pequenas onde possa ser explorado o equilíbrio da vida cotidiana; em exercitar uma fusão entre arquitetura e paisagem; ou mesmo na possibilidade de criar verdadeiros oásis na cidade grande, um modo de interagir o tumulto da cidade grande com a tranquilidade da vida doméstica tão percebida nos ideogramas chineses que se referem ao espaço e tempo. A incorporação de luz e sombra como uma experiência sensorial também é um dos pressupostos arquitetônicos atuais que faz referência a arquitetura tradicional, somada à adoção de jardins internos, mesmo em apartamentos urbanos. Segundo os arquitetos do escritório Roarc Renew, "A introspecção e a meditação são elementos fundamentais da cultura tradicional chinesa, e a arquitetura é responsável por criar espaços que permitam as pessoas se conectarem consigo mesmas. 0 sentido de lugar é um valor intrínseco à arquitetura, uma espécie de conexão divina entre os usuários e a materialidade do espaço" (in Miao, 2021).

\section{Algumas conclusões}

As reflexões contidas neste artigo estão baseadas no entendimento da Fenomenologia de que o espaço é uma concepção humana advinda da experiência no mundo. Sendo assim, o espaço experiencial supera a métrica, o funcionalismo, ao mesmo tempo que ele é portador de significados sensíveis. Quando ele é transformado em lugar de acontecimentos, de sentimentos, contribui para dar significado à existência, como diz Norberg-Schulz. 0 modo como a cultura oriental incide na construção desse significado 
existencial pode ser apreendido na Arquitetura. Paredes e tetos, céu, horizonte, luz e sombra, hábitos significativos diferenciam os lugares e ao mesmo tempo os reúne, quando os observamos como contribuições ao conhecimento. É assim que Tanizaki (2008), em “0 elogio da sombra", interpreta o espaço interior japonês como produto das sombras, ao afirmar que eles são permeados com a escuridão e, a partir da luz, criam sombras que determinam e caracterizam os interiores. Assim também Bachelard (2008) diz que o espaço não é algo a ser encontrado, mas que é necessário construí-lo sempre. Daí Norberg-Schulz dizer que a arquitetura deve ser entendida em termos de formas significativas.

Ao analisar as descrições fenomenológicas dos autores pesquisados e cotejá-los com o que apreendemos da linguística, podemos concluir que as culturas do Ocidente e do Oriente são diversas, mas que, se observadas pelo prisma fenomenológico, os entendimentos de espaço para a arquitetura podem ter em comum a busca por uma integração com o espírito do lugar, que considera aspectos culturais, sociais, construtivos e ambientais. Certamente, a Fenomenologia consegue mais se aproximar do modo de se relacionar com o mundo das culturas japonesas e chinesas, que tem raízes muito próximas, apesar de independentes. Isso porque reconhece a contribuição da subjetividade humana, tanto quanto o Ocidente defende o poder da razão como primordial. Então, se desde os Anos 60 do século XX, o Ocidente vivenciou o novo entendimento apresentado pela fenomenologia da Arquitetura, mais ou menos nesse mesmo período, o Japão resgatava o $M A$, como expressão e como método subjetivo. E a China, se não se apropriou minimalisticamente de um único símbolo, como o $M A$, vem buscando retomar os princípios orientais de integração com a natureza, da necessidade de contemplação, de estimular os sentidos. Nos três casos, o compromisso com o espírito do lugar está implícito.

Finalizamos essas reflexões exemplificando duas obras significativas, projetadas pelo arquiteto Tadao Ando e pelo escritório chines Shulin Architectural Design, onde percebemos o propósito de integração com o espírito do lugar, em cada uma das obras.

\section{A Casa Benesse Salão Oval - Tadao Ando}


Situada na Ilha de Naoshima, no mar de Seto-Naikai (um braço do Oceano Pacífico), o objetivo foi transformar a ilha pequena, sem grandes atrativos construtivos, em um projeto no qual a arquitetura estivesse em sintonia com a arte contemporânea e com a natureza. 0 local permite que artistas e arquitetos exibam seus trabalhos em distintas paisagens da Ilha, envoltos em uma ressonância cultural e histórica. 0 projeto da Casa Benesse dispõe de hotel, museu permanente, salas de exposições, restaurante, café, loja do museu e serviços. Em todo o edifício, incluindo suas varandas e pátios, estão dispostas obras de grandes artistas como Alberto Giacometti, Jasper Jones, Jackson Pollock, Richard Long, Christo, Kan Yasuda, entre muitos outros. Três anos depois de finalizado o hotel e o museu Benesse, Ando projetou o Salão Oval, finalizando-o em 1995.

É possível entender as obras de Tadao Ando, que se apropria do $M A$ como método, conhecendo o que ele diz.

Em minha opinião, existem três elementos necessários para a criação de arquitetura. Um deles seria o próprio material. Um material autêntico, possuidor de substancialidade, como o concreto aparente ou a madeira sem tinta. 0 segundo elemento seria a geometria pura, fundação ou estrutura que atribuísse presença ao projeto de arquitetura. E o último elemento é a natureza, com isso eu não me refiro à natureza bruta, mas sim a natureza tratada pelo homem. Ambiente caótico que ganha ordem pela ação humana, ou uma ordem abstraída da natureza. Trata-se da luz, céu e água, feitos como abstração. Quando esta forma da natureza adentra uma edificação composta por materiais autênticos e geometria pura, a própria arquitetura se rende à abstração pela natureza. Arquitetura adquire força e se torna esplendida somente quando seus materiais, sua geometria e a natureza estão integrados. (Tadao Ando, in Coutinho 2015: p. 135)

Segundo Coutinho (2015), numa demonstração de respeito ao ambiente natural, o acesso ao Salão Oval se dá por um funicular automatizado e guiado pelos hóspedes. 0 enquadramento da paisagem pode ser percebido desde a cabine, que a cada segundo, obriga o observador a fazer novas descobertas, tanto no espaço do museu, abaixo, quanto na própria natureza em todo o seu entorno. Com um diâmetro de 20 metros, o Salão Oval Benesse contém um espelho d'água corrente, uma escadaria cascata, um bar/cafeteria e apenas seis privilegiadas suítes. Todos os quartos miram o mar de Seto pelas varandas as engawas - e pela porta principal, miram o céu do Japão refletido no espelho d'água em forma elíptica. Os espaços $M A$ desse projeto são percebidos na delicadeza com que Ando evoca a natureza para dentro da edificação, e pelos caminhos meticulosamente 
projetados, que levam até o topo da montanha, numa escadaria. Em cada parte dessa edificação é possível descobrir um dos $M A$, referidos por Isozaki (p. 146-148).

Segundo Coutinho (2015), o salão oval pode ser considerado um Himorogi, o espaço onde o Kami vem à terra; por meio de um espaço oval, substituindo os quatro pilares, um espelho d'água reflete os galhos de árvores que circundam todo o vazio e a tama; pedras vistas no interior do espelho d'água retratam o antigo espaço de cerimônia para evocação do Kami. As figuras de número 1 a 4 são uma tentativa de exemplificar alguns ângulos de percepcao do Salão Oval.

Fotografias da obra Salão Oval

Figura 2 - Entrada e Muro de pedra

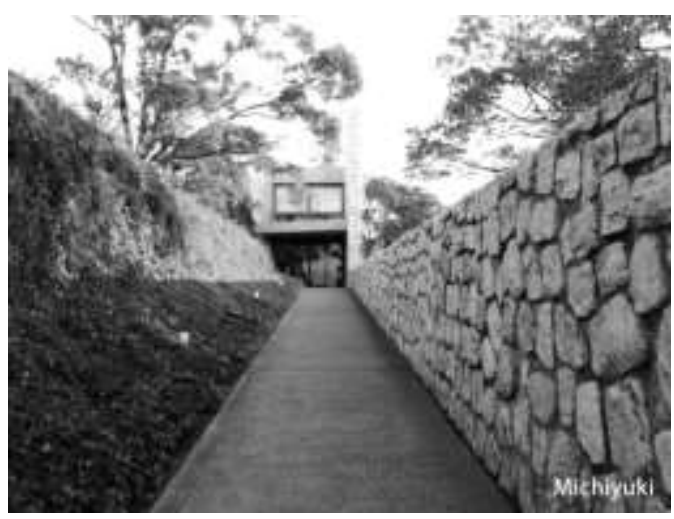

Figura 3 - Espelho d'água visto de cima

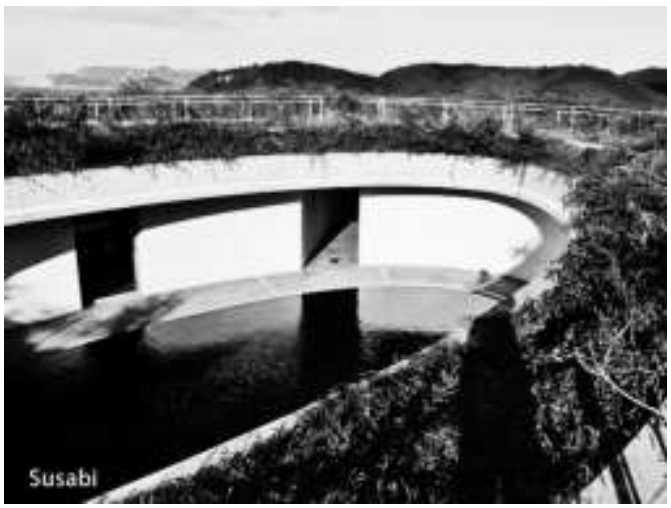

Figura 1 - Vista da ilha desde a cabine de acesso

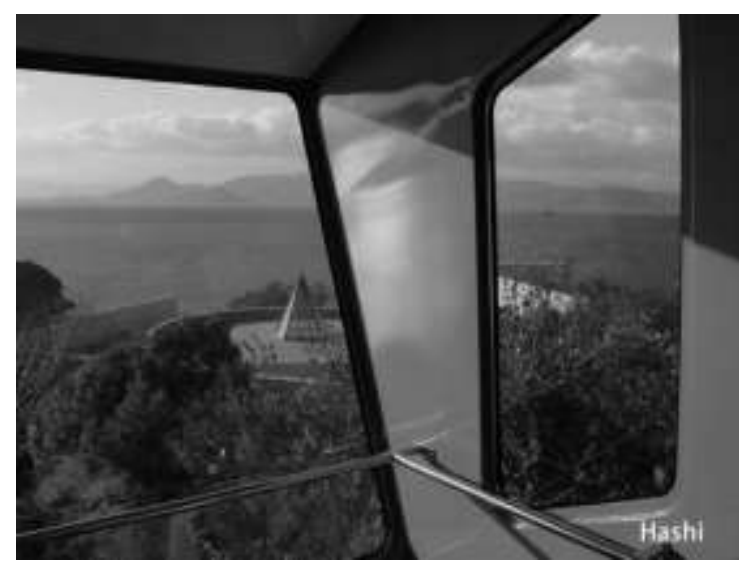

Figura 4- espelho d'água e visadas

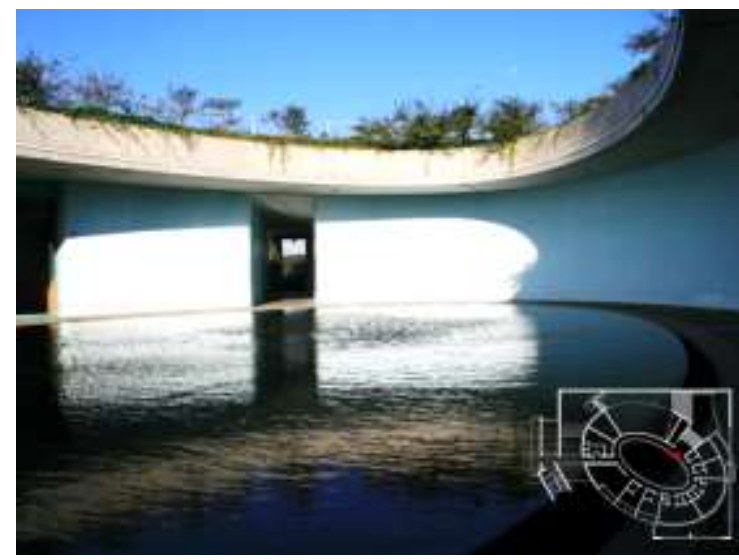

Fonte: Coutinho, 2015

O Mountain House - Shulin Architectural Design 
O Moutain House - uma biblioteca pública - se encontra no Condado de Wuyi, Jinhua, província de Zhejiang, uma aldeia antiga que se mantém há mais de cem anos. As casas da Aldeia estão implantadas em pequenos platôs, conformando a paisagem montanhosa e arborizada local. A biblioteca foi implantada de modo a preservar os caminhos, os pátios existentes e a paisagem local. Chama a atenção, além da busca por integrar-se ao espírito do lugar, a adoção do sistema construtivo como releitura do tradicional.

Segundo os arquitetos, a biblioteca tem o objetivo de ser um espaço de leitura sereno, que provoque sentimento de calma e que atraia as pessoas mais jovens e as crianças a vivenciarem a Montanha, ao mesmo tempo que oferece um espaço que estimula os sentimentos intuitivos dos aldeões. Daí o térreo ser plenamente franqueado às pessoas, numa integração dos caminhos locais com recantos para conversas, jogos, etc. Os espaços fechados da biblioteca ficam nos dois pavimentos superiores (Han, 2020). Um pequeno pátio integra diretamente edificação e natureza circundante, tornando-a, segundo os arquitetos, "mais relevante para a natureza, o tempo e o espaço":

O cenário do pátio parece que está à espera de um certo tempo - o sol se lançar em uma bela sombra, a chuva gotejar ou a brisa soprar. Nesses momentos, o pátio é definido como um espaço especial aguardando seu sentido de ser criado. A essência da arquitetura rural, a meu ver, é um estado em que pessoas e espaço, pessoas e natureza, e pessoas e tempo coexistem harmoniosamente. Este pátio faz com que isso aconteça ao incluir luz solar, chuva e ar no espaço interior (in Han, 2020)

\section{Fotografias da obra Mountain House}

$\begin{array}{ll}\text { Figura } 5 \text { - A biblioteca inserida na paisagem } & \begin{array}{l}\text { Figura } 6 \text { - a biblioteca inserida na } \\ \text { Aldeia }\end{array}\end{array}$
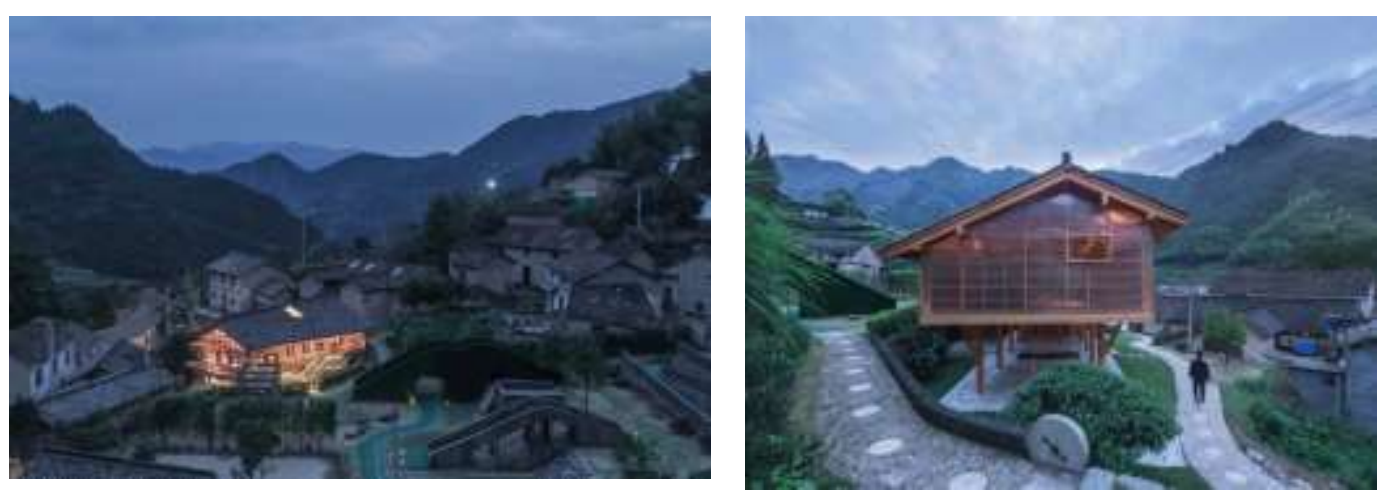
Figura 7 - o Térreo integrado a Aldei Figura 8 - o espaço sinestésico
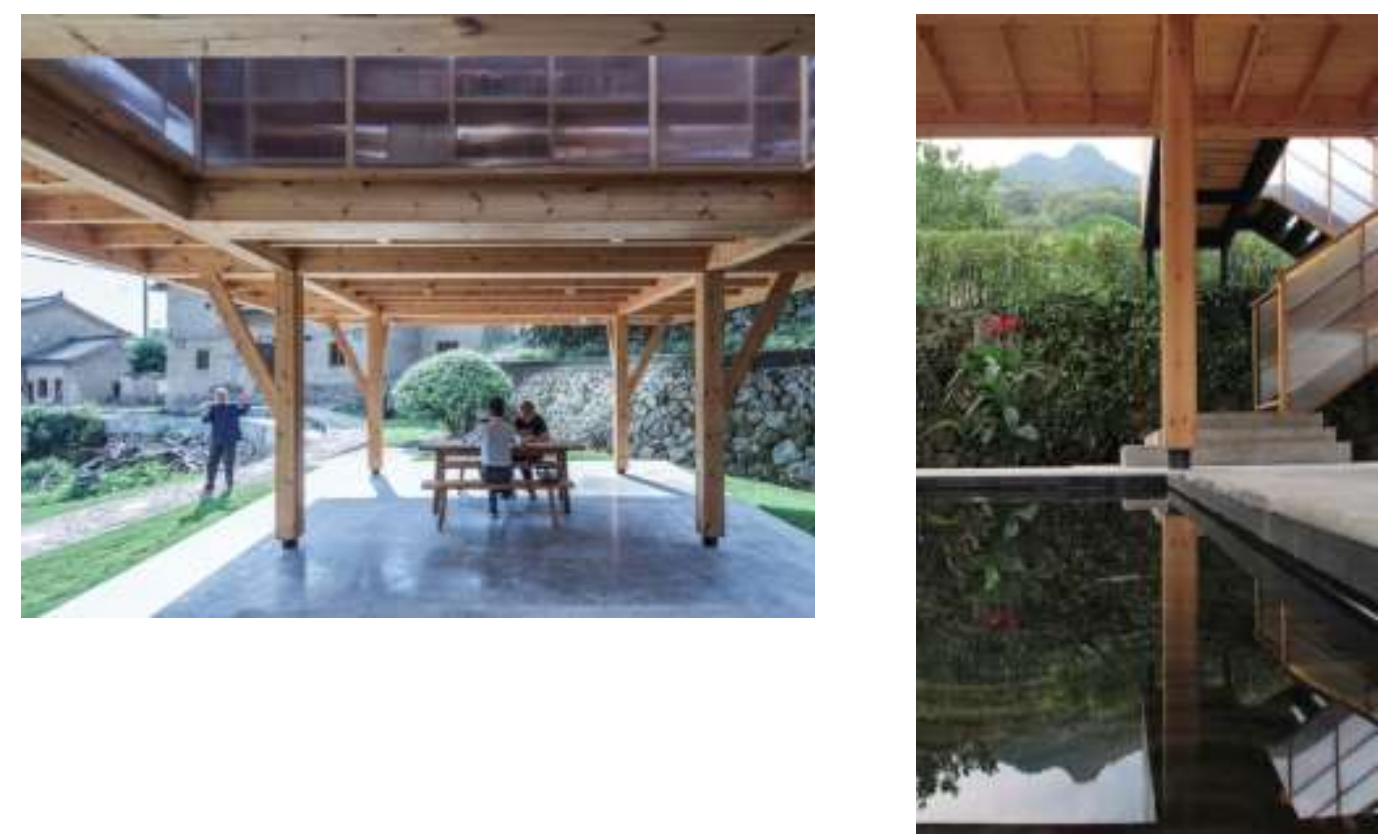

Fonte: Han, 2020

\section{Referências}

BACHELARD, Gaston. (2008). A poética do espaço. 2. ed. São Paulo: Martins Fontes.

BERQUE, A. (2010). Território e Pessoa: a identidade humana. Revista de Ciências Sociais da PUC-Rio, No. 6, jan-jul, 2010: p. 11-23.

BERQUE, A. (2015). Peut-on rationnallenet parler de "science naturante" (shizengaku 自 然学)? Scripta Philosophiæ Naturalis 7: p. 1-19.

CHU, Yu-Kuang. (1986). Interação entre Linguagem e Pensamento em Chinês. In: Campo, H. Ideograma. Lógica, poesia, linguagem. São Paulo: Cultrix: p.232 -262.

COUTINHO, Walkyria TSUTSUMI, F. (2015). O conceito MA. O conceito MA na conformação de espaços em Tadao Ando. Dissertação de Mestrado. Recife: Programa de Pós-graduação em Desenvolvimento Urbano.

GAO, Y. (2012). Contemporay Chineses architectural design in post theory era. Urban Environment Design, v. 8, p. 151-153.

GIEDION, Siegfried. (2004). Espaço, tempo e arquitetura: o desenvolvimento de uma nova tradição. São Paulo: Martins Fontes. 
HAN, Shuang. (2020). Mountain House in Mist / Shulin Architectural Design. Archidaly: https://www.archdaily.com/907416/mountain-house-in-mist-shulin-architecturaldesign?ad medium=office landing\&ad name=article.

HEIDEGGER, Martin. (1979). Que é Isto - a Filosofia? Conferências e escritos filosóficos. São Paulo: Abril Cultural.

HEIDEGGER, Martin. (1990). A Origem da Obra de Arte. Lisboa: Edições 70. NUNES, Benedito. 2002. Heidegger \& Ser e Tempo. Rio de Janeiro: Jorge Zahar.

HEIDEGGER, Martin. (2010). Construir, habitar, pensar (1951), in NESBITT, Kate (org). Uma nova agenda para a arquitetura: antologia teórica, São Paulo: Cosac Naify.

HEIDEGGER, Martin. (1979). O Fim da Filosofia e a Tarefa do Pensamento. Conferências e escritos filosóficos. São Paulo: Abril Cultural.

ISOZAKI, Arata \& OSHIMA, Ken. (2009). Arata Isozaki by Arata Isozaki e Ken Tadashi Oshima, Phaindon.

ISOZAKI, Arata. (2006). Japan - ness in architecture. Traduzido por Sabu Kohso, editado por David B. Stewart. London: MIT Press.

ISOZAKI, Arata. (2011). Katsura Imperial Villa. Phaidon, Londres.

ISOZAKI, Arata. (2000). MA: Space-time in Japan. Título original: Nijunen ato no kikanten, (MA -Twenty Years On), Exhibition Catalogue, Toky. Tokyo Geijutsu Daigaku,

ISOZAKI, Arata. (1990). Mitate no Shuho, Kajima Shuppankai.

MIAO, Scarlet. (2020). Do Antigo ao Moderno: construção modular na arquitetura chinesa. Archdaily. https://www.archdaily.com/949479/from-ancient-to-modernmodular-construction-in-chinese-timberarchitecture?ad medium=widget\&ad name=re. Acesso em: 02 Abr. 2021.

MIAO, S. (2021). Espaços de cura na China: o papel da arquitetura na experiência sensorial do espaço. Archdaily Brasil.

https://www.archdaily.com.br/br/958507/espacos-de-cura-na-china-o-papel-daarquitetura-na-experiencia-sensorial-do-espaco?utm_medium=email\&utm_sour , 2021. Acesso em: 20 Mar. 2021.

ESBIT, K. (2013). Uma nova agenda para a arquitetura. Antologia teórica 1965-1995. São Paulo: CosacNaify.

NETO, A. F. (2011). Heidegger e o inevitável diálogo com o Mundo Oriental. Goiania: Anais do Congresso de Fenomenologia da Região Centro-Oeste: p. 26-40.

NITSCHKE, Gunter. (1993). Ma - Place, Space, Void, in from Shinto to Ando. Studies in Architectural Antropoloy in Japan. London: Academy Editions; p. 48-61.

NORBERG-SCHULZ, C. (1999). Arquitetctura Ocidental. Barcelona: Gustavo Gili, 1999. 
NORBERG-SCHULZ, C. (1980). Existence, space and architecture. London: Existence, space and architecture, 1971.New York: Rizzoli.

NORBERG-SCHULZ, C. (2013). O Pensamento de Heidegger sobre Arquitetura. In Nesbir, Kate. Uma nova agenda para a arquitetura. Antologia teórica 1965-1995. São Paulo: CosacNaify: p. 461-474.

OKANO, Michiko. (2007). Ma - Entre- espaço da comunicação do Japão. Um estudo acerca dos diálogos entre Ocidente e Oriente. São Paulo.

PADUA, L. T. S. (2005). Topologia do Ser. Lugar, espaço e linguagem no pensamento de Martin Heidegger. Tese de doutoramento. Rio de Janeiro: PUC - Rio.

SAUSSURE, F. (1995). Curso de Lingüística Geral. Trad. De Antônio Chelini, José Paulo Paes e Izidoro Blikstein. São Paulo: Cultrix.

TANIZAKI, Junichiro. (2008). Elogio da sombra. Coleção Arquitetura. São Paulo.

TELLA, G. Miradas sobre Pekín: Arrollador proceso de renovación urbana. https://www.plataformaurbana.cl/plataforma/. Acesso em: 11 Abr. 2021.

TEIXEIRA, C. (2018). Cidades na cidade. A Bienal de Arquitetura de Shenzhen 20172018. Vitruvius; Arquitextos: maio.

TRIGOSO, Maria. (2014). " A (não) questão do tempo na tradição chinesa », Cultura [Online], Vol. 23 | 2006, posto online no dia 03 abril 2014, consultado em 01 de maio, 2019. URL : http://journals.openedition.org/ cultura/1437 ; DOI: 10.4000/cultura.1437

WU, Kuang-ming, (1995). "Spatiotemporal Interpenetration in Chinese Thinking", in HUANG, Chun-Chieh e ZURCHER, Erik (ed.), Time and Space in Chinese Culture, Leiden, E.J. Brill

Agradecimentos:

Universidade Católica de Pernambuco.

Universidade Federal de Pernambuco - Laboratório de Investigação do Espaço na Arquitetura - LIA

Cientista Política Mariana Yante, pelo apoio com as pesquisas sobre a língua chinesa. 